\title{
Saberes curriculares e práticas de formação de professores para o ensino médio: problematizações contemporâneas
}

\author{
Roberto Rafael Dias da Silva ${ }^{1}$ \\ ORCID: 0000-0001-6927-3435
}

\section{Resumo}

No decorrer das últimas duas décadas, no Brasil, pode-se constatar uma situação paradoxal no que tange às políticas educacionais destinadas ao Ensino Médio. Ao mesmo tempo em que ocorreu um crescimento vertiginoso no número de matrículas para essa etapa da escolarização, constata-se um declínio da institucionalidade da escola e uma intensificação de certa gramática da crise pedagógica. Impulsionado pelas constantes reformas educacionais, nota-se um forte investimento político no Ensino Médio tanto com foco na formação de professores quanto na produção de currículos escolares ajustados às novas demandas da sociedade do século XXI. Assim sendo, o presente texto considera, analiticamente, as relações estabelecidas entre o currículo escolar e as recentes políticas e práticas de formação de professores para o Ensino Médio implementadas no contexto brasileiro. Apoiando-se nos estudos curriculares e em tradições da teoria social contemporânea, sobretudo os escritos recentes de Gilles Lipovestsky, serão examinadas três cenas de formação inicial de professores ocorridas em cursos no Sul do Brasil, desenvolvidos por instituições públicas e privadas de ensino superior. Em tais experiências parece evidenciar-se um declínio da legitimidade acadêmica nos recentes modelos formativos em favor de uma centralidade das práticas, de uma ludificação dos procedimentos e um esmaecimento dos saberes curriculares e de sua função pública.

\section{Palavras-chave}

Formação de professores - Currículo - Ensino médio - Brasil.

1- Universidade do Vale do Rio dos Sinos (UNISINOS), São Leopoldo/RS, Brasil. Contato: robertoddsilva@yahoo.com.br.

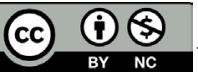




\section{Curricular knowledge and teacher's training practices for high school: contemporary problematizations}

\section{Abstract}

Over the past two decades, in Brazil, we have seen a paradoxical situation with regard to educational policies aimed at high school. While there was a soaring increase in the number of enrollments for this stage of schooling, there was also a decline in the institutionality of the school and an intensification of a certain grammar of the pedagogical crisis. Driven by constant educational reforms, a strong political investment in High School is observed focusing both on teacher's training and on the production of school curricula adjusted to the new demands of $21^{\text {st }}$ century society. Therefore, this text analytically considers the relationships established between the school curriculum and the recent policies and practices for teacher's training for High School implemented in the Brazilian context. Based on curricular studies and traditions of contemporary social theory, especially on recent writings by Gilles Lipovestsky, three scenes of initial teacher's training that took place in courses in southern Brazil, developed by public and private Higher Education Institutions, will be examined. Such experiences seem to show a decline in academic legitimacy in the recent training models in favor of a centrality of practices, a gamification of procedures and the fading of curricular knowledge and its public function.

\section{Keywords}

Teacher's training - Curriculum - High school - Brazil.

Bem-vindos à era das utopias do menos, das utopias light. Gilles Lipovetsky.

Ao colocarmos em análise os discursos pedagógicos e as políticas educacionais destinadas à formação de professores, conseguiremos constatar um intenso debate acerca das relações entre teoria e prática, associadas aos procedimentos formativos decorrentes dessa relação. Nóvoa (2009), por exemplo, defendia a importância de trazer os processos de formação de professores para o interior da profissão, seja pela necessidade de repensar as práticas escolares implementadas, seja para revitalizar os estudos sobre a ação docente e o trabalho escolar. Gatti (2010), na mesma direção, postulava que não seria mais conveniente ancorar os modelos de formação de professores na tradição disciplinar. Em suas palavras, tal formação: 
[...] não pode ser pensada a partir das ciências e seus diversos campos disciplinares, como adendo destas áreas, mas a partir da função social própria à escolarização - ensinar às novas gerações o conhecimento acumulado e consolidar valores e práticas coerentes com nossa vida civil. (GATTI, 2010, p. 1375).

Em linhas gerais, podemos sinalizar que os debates acerca da formação acadêmica e pedagógica dos professores perfazem a própria constituição do campo educacional no último século. No que tange à escolarização juvenil, esse debate adquire nuances específicas, sobretudo ao historicamente enfatizar o acesso ao ensino superior.

Estudos clássicos, como os de Mialaret (1991), por exemplo, indicavam que ambas as formações - teórica e prática - precisavam estar interligadas e não somente justapostas. Para os professores do ensino secundário, apontava o pesquisador francês que:

[...] a formação pedagógica, assim como toda a formação profissional, deve ultrapassar o plano da iniciação a algumas técnicas ou a prática de gestos profissionais simples para integrar a ação e o pensamento, a teoria e a prática. (MIALARET, 1991, p. 23).

Acerca desse modelo formativo, o pedagogo francês destacava, em seu primeiro princípio formativo, que "a formação pedagógica nunca substituirá o saber. Uma formação pedagógica não pode ser feita com ignorantes” (MIALARET, 1991, p. 91). A respeito do professor que atuará no Ensino Médio, com uma formação geralmente focada no âmbito teórico, Mialaret (1991) expõe que as articulações com a prática seriam indispensáveis, sem a perspectiva de esvaziar o campo teórico.

Atualmente, no Brasil, podemos constatar o advento de uma nova gramática formativa no que se refere à formação de professores. A literatura contemporânea tem sinalizado para um declínio do potencial teórico dos cursos de formação de professores, direcionando-se para uma centralidade nas práticas e nos procedimentos dela derivados (GATTI, 2010). Diante desse diagnóstico, o presente texto considera, analiticamente, as relações estabelecidas entre o currículo escolar e as recentes políticas e práticas de formação de professores para o Ensino Médio implementadas no contexto brasileiro. Apoiando-nos nos estudos curriculares e em determinadas tradições da teoria social contemporânea, sobretudo os escritos recentes de Gilles Lipovestsky, examinaremos três cenas de formação inicial e continuada de professores desenvolvidas por instituições públicas e privadas de ensino superior no Sul do Brasil. Em tais experiências, relatadas por professores participantes, parece efetivamente evidenciar-se um declínio da legitimidade acadêmica nos recentes modelos formativos em favor de uma centralidade das práticas, de uma ludificação dos procedimentos e de um esmaecimento dos saberes curriculares e de sua função pública.

As teorizações sociais desenvolvidas por Gilles Lipovetsky (2016) têm sido significativas para a compreensão das culturas contemporâneas. Seja no plano da política e da ética, seja no plano do consumo e das práticas culturais, as obras do filósofo francês catalisam importantes (e controversos) esforços para a compreensão de nosso tempo. Em sua obra mais recente, traduzida no Brasil sob o título Da leveza: rumo a uma civilização 
sem peso, Lipovetsky (2016) assinala que, atualmente, vemos desenvolver-se um culto à leveza. De maneira provocativa, acrescenta que nunca desejamos tanto a busca de modos de vida imediatos, superficiais e leves, tanto no design, na arquitetura, na moda e na publicidade quanto na política, na ética e na educação. Mais que isso, vale destacar, a lógica da leveza tornou-se o coração da economia (LIPOVETSKY, 2016).

Uma das tendências desses tempos, caracterizados como hipermodernos pelo autor em outra obra, remete-se à perspectiva de que "a vida dos indivíduos é marcada pela instabilidade, pois está entregue à mudança perpétua, ao efêmero, ao "mudancismo"” (LIPOVETSKY, 2016, p. 22). A política representativa ou a ética sacrificial, por exemplo, são estruturas pesadas demais para um tempo em que "as pesadas imposições coletivas deram lugar ao self-service generalizado, à volatilidade das relações e dos engajamentos" (LIPOVETSKY, 2016, p. 22). Em tais condições, emergem e consolidam-se formas subjetivas cada vez mais delineadas pelas lógicas da tecnociência, do mercado e do individualismo.

Certamente que tornar a vida mais leve é uma importante herança do século XVII, sobretudo pela prioridade em amenizar as opressões, o peso dos sofrimentos e das injustiças ou mesmo a simples busca por uma vida melhor. 0 que o filósofo francês assinala na obra em destaque é uma espécie de generalização social da leveza, na qual a leveza afirma-se como "uma norma geral, ideal universal e permanente, princípio fundamental da vida em sociedade estimulado pela ordem mercantil” (LIPOVETSKY, 2016, p. 35). A construção de uma civilização da leveza, sob essa argumentação, somente é possível através da proliferação de um capitalismo de sedução.

\footnotetext{
Ao mesmo tempo, é a própria economia que se encontra reorganizada pelo princípio de leveza, uma vez que o capitalismo de consumo funciona estruturalmente na sedução, na frivolidade, na renovação perpétua dos modelos. São lógicas que significam o advento de um sistema-moda que governa a ordem da produção e das necessidades. Nesse contexto, os objetos não se definem mais exclusivamente pelo seu estrito valor de uso, eles adquirem uma conotação lúdica ou tendência que os faz oscilar para o lado do leve: todo objeto, de alguma forma, torna-se um gadget pleno de inutilidade e de sedução lúdica. (LIPOVETSKY, 2016, p. 34).
}

A busca por referenciais hedonistas e lúdicos, coadunada pelo desejo de uma vida divertida e prazerosa, parece predominar na nomeada "civilização da leveza". Através da predominância desse capitalismo de sedução, afırma-se uma "retórica alegre e humorística que repudia a opressão e a gravidade do sentido em proveito de um clima recreativo permanente" (LIPOVETSKY, 2016, p. 42). Sem a pretensão de avaliar as condições da leveza e seus impactos, o ensaio de Lipovetsky que tomamos como ponto de partida para nossas reflexões proporciona um conjunto de provocações críticas para arriscarmos algumas formulações acerca da formação de professores para o Ensino Médio, derivadas de nossas incursões empíricas.

Caso consideremos as hipóteses desenvolvidas pelo filósofo francês, poderíamos afirmar que os processos de formação humana estariam ancorados na profusão de escolhas individuais, na inovação permanente e no entretenimento generalizado. Quais as implicações desse diagnóstico para analisarmos as políticas e práticas de formação de 
professores para o Ensino Médio? De que modo os saberes curriculares são mobilizados para a composição de uma escola justa e democrática? Como podemos descrever a função pública da docência em tempos de civilização da leveza?

\section{Formação de professores e escolarização juvenil: uma retomada}

A formação de professores no Brasil, de um modo geral, emerge no período posterior à Independência do país (SAVIANI, 2009). A preocupação em formar os profissionais que atuariam na formação dos estudantes, ainda que de modo intermitente, atravessa o século XIX. Todavia, será na virada para os anos 1900 que encontraremos o desenvolvimento e a expansão do modelo das Escolas Normais. De acordo com Saviani, em perspectiva histórica, "uma nova fase se abriu com o advento dos institutos de educação, concebidos como espaços de cultivo da educação, encarada não apenas como objeto do ensino, mas também da pesquisa" (SAVIANI, 2009, p. 145). Seja pela formação de uma cultura geral, seja com foco nos saberes profissionais, ainda que com muitas críticas, assistimos ao advento de uma cultura de formação pedagógica em nosso país (VIDAL, 2001).

No que tange à formação de professores para a nomeada educação secundária, a organização e a implementação de cursos de licenciatura irá se estabelecer a partir dos Institutos de Educação de São Paulo e do Distrito Federal, na década de 1930. Tais instituições serviram de base para os "estudos superiores de educação" no Brasil (SAVIANI, 2009). A forma predominante na organização desses cursos era o conhecido modelo "3 + 1" (VICENTINI; LUGLI, 2009), no qual os graduandos cursavam três anos em estudos específicos de sua área de conhecimento, seguidos por mais um ano com disciplinas pedagógicas.

Certamente que, para a educação secundária, esse modelo de formação superior não se colocava como o único modelo formativo, nem mesmo situava-se como uma estrutura homogênea.

A diversidade dos cursos decorreu das peculiaridades do magistério primário, secundário e superior, bem como das especificidades das instituições nos mais diversos estados do país. Acima de tudo, as iniciativas para garantir diplomas a todos os docentes refletiram os debates travados no campo educacional por políticos, educadores, intelectuais e associações em torno das alternativas tomadas como mais apropriadas para a formação do magistério. (VICENTINI; LUGLI, 2009, p. 65-66).

Assim sendo, parecia estabelecer-se uma lógica na formação do educador secundário que priorizava os saberes disciplinares, ainda que tensionada por elementos advindos da prática profissional. Nas palavras de Saviani (2009, p. 151), "tudo indica que na raiz desse dilema está a dissociação entre os dois aspectos indissociáveis da função docente: a forma e o conteúdo". Na primeira metade do século XX, a partir da tarefa de institucionalizar a escola pública no país, serão os educadores de inspiração escolanovista que mobilizarão esforços na direção de ultrapassar esse dilema. 
A busca por uma escola nova e ativa conduziu pensadores como Anísio Teixeira e Lourenço Filho a defenderem que a escolarização não poderia ser institucionalizada no contexto brasileiro, valendo-se das "artes de ensinar da pedagogia moderna".

\begin{abstract}
No campo normativo da nova pedagogia que passa a reivindicar para si o monopólio do moderno, o método é dissociado da prática, das artes de fazer, do que decorrem importantes deslocamentos nas estratégias de formação docente. A produção de condições materiais que favorecessem a imitação inventiva de métodos é substituída por estratégias que visam subsidiar a prática docente com um repertório de saberes autorizados, propostos como os seus fundamentos ou instrumentos. (CARVALHO, 2000, p. 119).
\end{abstract}

Certo deslocamento de uma cultura pedagógica tradicional para a proliferação de métodos ativos, com maior ou menor intensidade, perfaz a composição da agenda educacional do século XX. Silva (2017), a seu modo, sugere que a emergência da Contemporaneidade Pedagógica no Brasil teve conotações específicas, ora vinculadas à crítica aos modelos instrucionais, ora atrelada ao combate às desigualdades sociais. $\mathrm{Na}$ percepção do autor, merece atenção no âmbito das políticas curriculares que:

[...] o ideal republicano da 'escola comum para todos', em nosso contexto, estabeleceu-se através da centralidade das subjetividades dos estudantes, por outros itinerários conseguindo reforçar as lógicas individualizantes das políticas curriculares atuais. (SILVA, 2017, p. 14).

No que tange ao Ensino Médio, a formação de professores encontrou maior relutância para a mobilização de métodos diferenciados, da mesma forma que inúmeros impedimentos foram encontrados para os processos de mudança. Nas últimas décadas do século passado, assistimos ao advento de um conjunto de reformas curriculares, associadas simultaneamente a publicação de novos estudos pedagógicos que direcionam o foco na formação de professores para a prática. Sem a pretensão de esgotar esse exercício de reconstrução histórica da questão, a virada de século apresentou-nos a viabilidade de programas que intensificam a relação entre universidade e escola (GOMES; SOUZA, 2016), ou mesmo que conduziram a formação continuada dos professores para o interior das ações governamentais em larga escala (DANTAS, 2017).

$\mathrm{Na}$ perspectiva internacional, em um breve exercício de revisão da literatura, valeria a pena indicar os estudos de Nóvoa (2009), Tardif e Moscoso (2018), Popkewitz (2015) e Biesta (2018), ainda que não sejam convergentes. De acordo com Nóvoa (2009, p. 15), atualmente podemos constatar uma "inflação retórica sobre a missão social dos professores”. Um conjunto de novos discursos pedagógicos, derivados tanto dos setores acadêmicos quanto das organizações internacionais, tem ampliado os controles sobre a atividade dos professores e os limites para sua autonomia profissional. Deriva-se desse cenário uma defesa das práticas profissionais como dispositivos orientadores das políticas de formação de professores configurando determinadas comunidades de práticas. De acordo com Nóvoa, trata-se de: 
[...] um espaço conceptual construído por grupos de educadores comprometidos com a pesquisa e a inovação, no qual se discutem ideias sobre o ensino e aprendizagem e se elaboram perspectivas comuns sobre os desafios da formação pessoal, profissional e cívica dos alunos. (NOVOA, 2009, p. 21).

Sob um prisma analítico mais abrangente, Tardif e Moscoso (2018) pretendem revitalizar a noção de profissional reflexivo, derivada dos estudos de Donald Schön, ampliando os sentidos dessa noção no campo educacional. Em sua argumentação, uma retomada da reflexividade dos professores poderia ser pensada enquanto experiência social, reconhecimento ou crítica às relações de dominação. Desde outro enquadramento, Biesta (2018) tem defendido a necessidade de redescobrirmos o ensino, entendido enquanto uma tarefa pública. A defesa de uma sociedade de aprendizagem, segundo o autor, tende a favorecer relatos "equivocados sobre o que é o ensino, o que é o trabalho do professor e o que os alunos podem obter dos encontros com ensino e com os professores” (BIESTA, 2018, p. 22-23).

Vale ainda destacar a perspectiva derivada dos estudos de Popkewitz (2015) ao estabelecer uma crítica mais contundente dos modos pelos quais a centralidade das práticas tende a fabricar determinados sistemas de raciocínio pedagógico. A ênfase atribuída às práticas nos programas de formação docente estabelece o professor "como o sujeito e o objeto da mudança o que produz um determinismo ontológico. A prática se define como possuidora de certos processos que estabelecem a perícia do professor" (POPKEWITZ, 2015, p. 434). As teorias pedagógicas produzidas nessas relações engendram novas inserções profissionais e regulam a atividade dos professores, definindo o que conta como uma boa prática.

Ao longo desta seção, procuramos mapear os sentidos atribuídos à formação docente para a escolarização juvenil e, posteriormente, revisamos como essa centralidade das práticas tem sido recebida na literatura (brasileira e estrangeira). Na próxima seção, ampliaremos este debate atribuindo visibilidade aos diagnósticos sociológicos acerca de nossas sociedades. À luz da teorização social contemporânea, sobretudo do pensamento de Gilles Lipovetsky, esboçaremos alguns dilemas da formação de professores para a escolarização juvenil em nosso tempo.

\section{Dilemas da formação de professores na contemporaneidade: um diagnóstico}

São variadas as teorizações sociais contemporâneas que permitem com que ampliemos nosso diagnóstico acerca dos processos de formação humana na contemporaneidade. Com o sociólogo Maurizio Lazzarato (2013), em sua obra Il governo dell'uomo indebitato, podemos direcionar nossa reflexão para examinar a formação permanente nos termos da relação entre crédito e débito. Dessa forma, seria possível pensar a própria política do capital. De acordo com o autor, "pela primeira vez, desde a existência do capitalismo, não é mais a relação capital-trabalho que está no centro das políticas econômica, social e política" (LAZZARATO, 2013, p. 10). Com o advento das políticas de inspiração neoliberal, e os consequentes trinta anos em que se consolida a lógica da financeirização, as mudanças tornam-se evidentes. Aliás, cumpre explicitar que, na esteira do pensamento de 
Foucault, Lazzarato reconhece que a financeirização estende-se na direção do trabalho, no mundo produtivo, no sistema político, no bem-estar e no consumo. Em outras palavras, as modalidades de intervenção derivadas da financeirização espalham-se por toda a vida social, governando os próprios sentidos planejados para cada um dos indivíduos.

A crise do Estado contemporâneo, em suas dívidas crescentes e dificuldades na promoção do desenvolvimento, apresenta-se como uma das nuances referentes a essa questão, uma vez que tais formas de regulação chegam ao nível da própria vida. Na acepção de Lazzarato (2013, p. 12), “todos nós estamos em dívida”. Esse argumento materializa-se na própria formulação de capital humano, cada vez mais direcionada à autocapitalização, pela via dos empreendimentos de si mesmo. A crise, enfim, não é apenas de ordem econômica, social ou política.

\begin{abstract}
É antes de tudo uma crise do modelo subjetivo neoliberal, encarnado no capital humano. 0 projeto de substituir o trabalhador assalariado do fordismo pelo empreendedor de si, transformando o indivíduo em uma empresa individual que gerencia sua própria capacidade como um recurso econômico em capitalização entrou em colapso com a crise dos subprimes. Deste ponto de vista, a situação dos países ricos e dos países emergentes antes de divergirem, - com o declínio e a estagnação dos primeiros e o crescimento e o progresso dos segundos - converge na produção de um mesmo modelo de subjetividade, apesar de seu repetido fracasso: o capital humano (o neoliberalismo não mais nada a propor). (LAZZARATO, 2013, p. 15).
\end{abstract}

Na argumentação proposta por Lazzarato (2013, p. 18), “o capital humano implica um máximo de privatização econômica e um máximo de individualização”. Com a redução das políticas sociais, o empresário de si vê-se dirigido a reinventar sua formação para competir individualmente. No avesso dessa lógica, importa enaltecer que milhões de pessoas continuam sendo lançadas diariamente nas condições da pobreza, ampliando as matrizes de desigualdade.

Dando continuidade a essa abordagem, Michael Peters (2016), inspirado em uma argumentação nietzschiana, também se propõe a explicar as relações capitalistas contemporâneas a partir da relação entre credores e devedores, na medida em que se constituem em um tipo de "economia biopolítica da dívida". De acordo com o autor, "a divida [opera] como um instrumento ou mecanismo para o governo da subjetividade que funciona à margem do dinheiro, poder, economia e moral" (PETERS, 2016, p. 4). Reposicionando a dívida como um modo de vida, no contexto do neoliberalismo, problematiza a perspectiva de uma "economia educacional da dívida", associada a uma financeirização da esfera produtiva.

\footnotetext{
Nesse regime, a monopolização e a privatização têm avançado rapidamente. Um dos efeitos da financeirização e da crise econômica tem sido popularizar um debate sobre cortes econômicos e a 'política da austeridade' em toda a linha de serviços públicos prestados a nível de estado com cortes maciços para a educação em todos os aspectos, ataques à negociação coletiva entre patrões e empregados, e a demissão de milhares de professores. (PETERS, 2016, p. 12).
} 
Todavia, em nossa compreensão, o exame da análise das novas configurações subjetivas emergentes desse cenário não se esgota nas dimensões do capital humano e da economia educacional da dívida. Em outras palavras, as subjetividades contemporâneas não se limitam à fabricação do Homo Economicus. De acordo com Lipovetsky (2007), pensador escolhido para orientar nossa reflexão neste texto, atualmente a constituição dos sujeitos tem sido delineada a partir de suas "escolhas e decisões individuais", na medida em que "a vida privada e a vida pública foram assumindo uma feição mais livre" (LIPOVETSKY, 2007, p. 2). Entretanto, de forma paradoxal, a promoção do individualismo favoreceu o engendramento de uma "atmosfera de ansiedade". Nas palavras do autor, tratase de "uma atmosfera de entretenimento e distensão contínuos, de bem-estar consolidado, [que] coexiste com a intensificação dos obstáculos para se viver o aprofundamento do malestar subjetivo" (LIPOVETSKY, 2007, p. 4). Estaria emergindo uma sociedade da decepção, inflacionada pelas experiências públicas e privadas de desapontamento em nosso tempo.

Lipovetsky explica ainda que estamos diante de uma cultura hipermoderna na qual as culturas marcadas pela ansiedade, pela frustração e pela decepção configuram-se como características importantes. Mediante uma situação de crise ou enfraquecimento dos dispositivos institucionais, em muito demarcadas pelas práticas consumistas, os indivíduos veem-se em uma espécie de perpétua carência.

Como o mercado sempre nos sugere algo mais requisitado, aquilo que já possuímos acaba ficando invariavelmente com uma conotação decepcionante. Logo, a sociedade de consumo incita-nos a viver num estado de perpétua carência, levando-nos a ansiar continuamente por algo que nem sempre podemos comprar. Assim, ficamos implacavelmente distantes da condição de plenitude, sempre descontentes, condoídos em razão de tudo aquilo que não podemos proporcionar a nós mesmos. 0 consumo no sistema de mercado seria um pouco como o tonel das Donaides, que orquestra com sucesso o descontentamento e a frustração de todos. (LIPOVETSKY, 2007, p. 23).

Paradoxalmente, ainda acompanhando a perspectiva de Lipovetsky, uma das nuances da cultura contemporânea evidencia-se na busca pela leveza; não mais como um estilo de vida individual, mas impondo-se como um "modo de funcionamento e de cultura global” (LIPOVETSKY, 2016, p. 21). De acordo com o filósofo francês, em elaboração recente, os setores da economia de consumo são regidos pelas lógicas da eterna mudança, da inconstância e também da sedução. Tal como apresentam-se nas condições culturais de nosso tempo, "universo da necessidade e universo fútil se entrelaçam, se cruzam, se hibridam: a lógica da leveza não é mais o 'outro' da realidade econômica; ela é seu coração" (LIPOVETSKY, 2016, p. 21). Poderíamos assinalar, sob esta perspectiva, que estaríamos ingressando em uma era de "triunfo da leveza", mobilizada pelos variados recursos advindos de um "capitalismo de sedução".

Com as mudanças culturais, transcorridas no final do século XX, a vida individual e coletiva direcionou-se para a busca do mais leve. De acordo com o filósofo, parecem emergir novas formas de subjetividade caracterizadas pelo individualismo e pelo "mudancismo", na medida em que "a individualização extrema da relação com o mundo constitui a principal dinâmica social situada no coração da revolução do leve” (LIPOVETSKY, 2016, p. 22). Os indivíduos contemporâneos não mais aspiram revoluções ou libertações, dimensionadas 
na ordem de uma vida coletiva, mas sonham com a leveza - com uma mudança de vida, seja no trabalho e nas relações de consumo, seja na busca de bem-estar e na religiosidade. Conforme Lipovetsky, em sistematização bastante perspicaz:

[...] a civilização emergente do leve não significa a manifestação de um modelo único de leveza, ainda que sejam as mesmas grandes forças estruturantes da hipermodernidade - a tecnociência, o mercado e o individualismo - que estão na base de sua recente preeminência social. (LIPOVETSKY, 2016, p. 30).

Em sua multiplicidade de formas, a leveza pode estar associada ao bem-estar, à economia e ao consumo.

Duas dimensões precisam ser destacadas desse diagnóstico. A primeira dimensão remete-se à predominância de "uma cultura cotidiana marcada pela leveza hedonista" (LIPOVETSKY, 2016, p. 34). Essa cultura cotidiana assenta-se na busca pela leveza do viver e pode ser visibilizada na publicidade, no lazer, na moda, nas atividades e jogos diversos que perfazem as dinâmicas culturais da atualidade. Nas palavras de Lipovetsky (2016, p. 36): "com o culto de bem-estar, da diversão, da felicidade aqui e agora, o que predomina é um ideal de vida leve, hedonista, lúdica”. Esse ideal de vida encontra possibilidades de intensificação em outro arranjo econômico.

A segunda dimensão diz respeito à própria reorganização da economia sob as condições do princípio da leveza. Segundo a argumentação desenvolvida pelo filósofo, importa enaltecer que "o capitalismo de consumo funciona estruturalmente na sedução, na frivolidade, na renovação perpétua dos modelos” (LIPOVESKY, 2016, p. 34). 0 consumo não mais se orienta apenas pelo valor de uso. De forma assemelhada ao que destacamos anteriormente, "não é mais a gravidade das máquinas de produção, mas sim uma espécie de leveza transestética que envolve os bens de consumo" (LIPOVETSKY, 2016, p. 34).

Em linhas gerais, poderíamos sinalizar que as condições sociais emergentes no contexto do capitalismo contemporâneo trazem implicações significativas para pensarmos os processos de formação humana. Com Lipovetsky, podemos dimensionar um diagnóstico pluralista bastante pertinente, uma vez que não limita a descrição das formas atuais de subjetividade ao domínio do Homo Economicus, favorecendo uma ampliação do escopo de nossas análises. Em outras palavras, podemos pensar os processos de formação de professores para o Ensino Médio à luz das condições da hipermodernidade, em que as lógicas do indivíduo, da tecnociência e do mercado podem operar como grade explicativa para descrevermos esse cenário. A seguir, apresentaremos três incursões empíricas realizadas em cursos de formação inicial de professores, privilegiando a composição de uma abordagem crítica acerca dessas práticas curriculares.

\section{Práticas curriculares em licenciaturas no Sul do Brasil: incursões empíricas}

Silva (2018), em exercício analítico recentemente publicado, descreveu a perspectiva de que as práticas curriculares atualmente desenvolvidas no ensino médio eram regidas pela lógica da estetização pedagógica. Ao aceitar essa hipótese e procurar levá-la adiante, 
procuramos mapear um conjunto de práticas promovidas no âmbito dos cursos de formação de professores desenvolvidos por universidades públicas e privadas situadas no Sul do Brasil. Nossa coleta deu-se pelo acesso aos documentos públicos disponibilizados nos sites dos diferentes cursos, através de seus avisos, recomendações e orientações dadas aos seus estudantes. Acompanhamos as descrições das práticas curriculares de cinco cursos de licenciatura, as quais sistematizaremos neste texto a análise de três cenas pedagógicas derivadas dessas incursões empíricas.

A opção por acompanhar determinadas processos formativos que ocorriam em cursos de licenciatura permitiu-nos ampliar o olhar para além das concepções pedagógicas que instituíam esses cursos para conseguir mapear o regime de implementação de suas práticas curriculares. Entendemos por práticas curriculares as variadas formas de organização do conhecimento escolar que perfazem os procedimentos de planejamento, ação e avaliação pedagógica. De acordo com Pacheco (2014), tais práticas:

[...] são dominadas por uma configuração estável no tempo e no espaço, pois as suas formas de legitimação e transmissão baseiam-se na instrumentação do saber através da convergência e do padrão estável de procedimentos. (PACHECO, 2014, p. 78).

Distanciando-se de qualquer uniformidade, sua promoção é desencadeada a partir de diferentes atores.

Assim, as práticas curriculares dependem, de uma forma substantiva, da organização do conhecimento, primeiramente determinado pelo Estado em termos da balizagem (geralmente, em níveis e ciclos) e da periodização dos percursos escolares (em anos de escolaridade). É o conhecimento, por assim dizer, que traduz, por um lado, o que o currículo é em todos os seus processos e práticas de concepção, realização e avaliação, e, por outro, o modo como podem ser analisadas as teorias curriculares. (PACHECO, 2014, p. 78).

A primeira prática curricular que escolhemos examinar neste estudo refere-se a um curso de licenciatura em Letras, ofertado por uma universidade pública federal no Sul do Brasil na modalidade à distância. A disciplina de Introdução ao estudo da linguística trazia como uma de suas atividades avaliativas no segundo semestre de 2017 uma tarefa que despertou nossa atenção. Mesmo diante da complexidade conceitual que perpassa essa área do conhecimento, associada a sua pertinência para a formação dos futuros professores de Língua Portuguesa, a atividade avaliativa solicitava que, utilizando as tecnologias digitais, os estudantes elaborassem um meme acerca de uma temática atual e que tal figura estabelecesse alguma relação com os conteúdos de Linguística estudados no período. Em linhas gerais, podemos definir que um meme é uma imagem, vídeo ou desenho, de caráter humorístico, que serve para difundir uma ideia na internet.

Sem a pretensão de estabelecermos um sentido defınitivo para a avaliação das aulas ou para a condução da prática mobilizada pela professora, parece-nos que há uma preocupação em justapor o processo formativo a uma lógica do entretenimento generalizado. A busca por tornar as aulas mais leves torna-se um imperativo pedagógico 
de nosso tempo. Conforme analisamos anteriormente, de acordo com Lipovetsky (2016), a leveza constitui-se como uma das principais dimensões da vida contemporânea. De forma ambivalente:

[...] a ligação com o imediato, o superficial e o leve não se reduz mais a uma atitude individual em relação à vida ou aos outros. Ela agora se impõe como modo de funcionamento econômico e de cultura global. (LIPOVETSKY, 2016, p. 21).

A lógica da leveza, ao mesmo tempo em que se vincula às dinâmicas sociais da hipermodernidade, também está no cerne das novas formas de economia. Em sua percepção, a revolução do leve é levada adiante por uma variedade de instrumentos.

\begin{abstract}
A leveza que era um ideal estilístico ou um defeito moral tornou-se uma dinâmica global, um paradigma transversal, um "fato social total" carregado de valor tecnológico e econômico, funcional e psicológico, estético e existencial. A partir de então, proliferam as esferas que expressam o combate do leve contra o pesado. A era hipermoderna é inseparável de uma revolução multidimensional da leveza cujo ritmo é vertiginoso. (LIPOVETSKY, 2016, p. 24).
\end{abstract}

Importante enaltecer que o curso não negligencia a importância da Linguística para a formação do futuro professor; antes disso, reinscreve estes conhecimentos em uma atmosfera lúdica e de entretenimento. Constata-se uma preocupação em ajustar o currículo da licenciatura às demandas tecnológicas de nosso tempo; no entanto, desperta nossa preocupação a possibilidade de fragilizar a importância do conhecimento elaborado. De outra perspectiva, Newton Duarte (2011), ao se referir às pedagogias contemporâneas, alertava para o risco da predominância de práticas relativistas. Em suas palavras, “o relativismo, tanto no aspecto epistemológico como no cultural, leva a uma ausência de referências para a definição do que ensinar na escola às novas gerações" (DUARTE, 2011, p. 246-247).

A segunda prática curricular que examinamos diz respeito a um programa de formação de professores de uma universidade pública gaúcha que estabelece em seu currículo acadêmico uma forte preocupação com as práticas pedagógicas desenvolvidas nas escolas públicas. 0 curso de licenciatura em Filosofia, ofertado para professoras da educação básica que ainda não têm a formação inicial, traz como principal característica o desenvolvimento de um blog, no qual cada estudante precisa realizar, individualmente, quinze postagens por semestre. Para além das atividades derivadas das disciplinas integrantes da grade curricular e da realização de um seminário semestral que integra as experiências formativas das futuras professoras, chama atenção a necessidade de publicizar cada reflexão ou experiência desenvolvida ao longo do período.

Se na primeira cena analisada a ênfase recaía sobre o entretenimento generalizado, nesta podemos indicar a necessidade de inovação permanente e, mais que isso, na divulgação permanente das boas práticas. Acerca da divulgação permanente, seria oportuno retomar a crítica apresentada pelo filósofo Byung Chul-Han (2014) acerca de certa ditadura da transparência, isto é, somos interpelados a divulgar nossas experiências para que as pessoas possam curtir. Nossas ações precisam de espectadores, o que pode 
nos levar a "uma crise da liberdade com maior alcance, pois agora afeta mesmo a vontade livre” (HAN, 2014, p. 14). Acerca da busca de boas práticas, como assevera Zeichner (2013), precisamos tomar cuidado para que isso não signifique uma roteirização do trabalho docente e uma consequente precarização de sua formação epistemológica.

Mais uma vez recorrendo a Popkewitz (2015), a centralidade das práticas tende também a fabricar modos específicos de tornar-se docente. Isto é, "ironicamente, a prática é um referente de uma teoria sobre em que se fixar e o que pensar como objetos de reflexão - e o que deveria ser" (POPKEWITZ, 2015, p. 436). Se durante a modernidade pedagógica os processos educacionais estiveram centrados no campo da teoria; hoje, provavelmente por motivos tratados na seção anterior, há um deslocamento para a dimensão prática. 0 pesquisador estadunidense justifica essa virada nos processos formativos a partir de determinadas teorias psicológicas.

A prática consiste em teorias psicológicas ordenadas. Estas proporcionam as distinções e guias para organizar o que é visto como práticas promissoras e permitem orientar intervenções que modificarão as práticas. As teorias sobre a aprendizagem, por exemplo, são evocadas como teorias "práticas" para organizar as práticas educativas dos professores e permitir a mudança. (POPKEWITZ, 2015, p. 437).

Quando examinamos as práticas formativas nos cursos de licenciatura, despertou nossa atenção o fato de que há uma articulação entre os saberes econômicos, os princípios formativos e o mundo do design. A centralidade das práticas, assim, figura como:

[...] uma receita, encarnando um conjunto organizado de princípios para atuar e pensar acerca de como as coisas se mantem unidas, e o que é aceito como universal sobre o professor idealizado. (POPKEWITZ, 2015, p. 440).

A terceira cena que apresentaremos a seguir diz respeito a um possível esmaecimento dos saberes curriculares e de sua função pública. Um núcleo de educação a distância (EAD) de uma grande universidade privada brasileira anunciava nos variados meios de comunicação um novo modelo de organização de seus cursos de licenciatura. Para além da comodidade de estudar em casa e no horário em que julgar conveniente, o anúncio publicitário destacava que a personalização seria o principal diferencial competitivo daquele curso. Por meio das plataformas digitais, associadas ao desejo de ajustar o currículo da licenciatura ao perfil formativo do estudante, notava-se que o curso EAD prometia a oferta de conteúdos, materiais e ambientes virtuais potencializados pela capacidade de escolha dos futuros profissionais. Lançando mão de recursos atrativos, o curso prometia ainda o envolvimento com pessoas dinâmicas e interativas, assim como o empoderamento para poder customizar sua formação como profissional atendendo às demandas do século XXI.

A perspectiva de customizar os currículos de acordo com o perfil dos estudantes tem se constituído como recorrente nas práticas curriculares contemporâneas (SILVA, 2017). Porém, importante fazer uma ressalva no que tange aos efeitos da customização em tais cursos. Diferentemente da educação básica que tal prática pode contribuir para uma intensificação das desigualdades, na educação superior pode contribuir para uma 
fragilização dos saberes profissionais e, ao mesmo tempo, um esmaecimento da função pública desses cursos. Uma característica importante desses currículos é o modo pelo qual são planejados a partir de uma lógica de “estetização pedagógica” (SILVA, 2018).

Nessa composição analítica, outro ponto que podemos considerar remete-se à constatação de que o atual desenvolvimento industrial atribui centralidade para o design. De acordo com Lipovetsky e Serroy (2015), está em curso um processo de industrialização em que:

[...] a intensificação da concorrência e as novas expectativas dos consumidores levaram ao advento de uma economia pós-fordiana marcada pelo imperativo da inovação e da diversificação dos produtos". (LIPOVETSKY; SERROY, 2015, p. 226-227).

A busca pela inovação e pela diversificação caracterizam o declínio de um modelo de produção centrado na repetição e favorecem a emergência de economia de variedade.

Novas exigências dos consumidores, associadas a uma proliferação da variedade de oferta, encaminham para uma busca permanente de renovação. 0 ritmo acelerado da inovação permite com que o design passe a ocupar mais espaço na busca por outras formas de satisfação dos públicos.

Cada vez mais opções e novidades aceleradas, variações e declinações de produtos: isso traduz o advento de um design cada vez mais sob a influência do mercado, o peso que a esfera comercial tem na criação industrial, um capitalismo estético em que triunfa um mercado de demanda movimentado pelo cliente, em lugar do mercado da oferta, que dominava anteriormente, em que os produtores ofereciam seus produtos a consumidores que tinham poucas opções. (LIPOVETSKY; SERROY, 2015, p. 229).

Todo e qualquer objeto a ser comercializado é projetado a partir das leis da "criação-estilo"; isto é, "hoje é o próprio design que, por suas tendências, contribui para fazer a moda” (LIPOVETSKY; SERROY, 2015, p. 231). Esse cenário intensifica-se em um cenário em que está em curso um processo de globalização das economias criativas. Uma característica importante desse cenário é o caráter emocional dessa forma de design que agora predomina. De acordo com Lipovetsky e Serroy (2015, p. 250), “o design hipermoderno propõe formas de qualidades sensíveis, centradas no imaginário do conceptor e nas emoções do consumidor". Quando direcionamos nossa reflexão para as práticas curriculares de formação de professores para o Ensino Médio, reparamos que essas lógicas podem conduzir a novos regimes de implementação da política de formação de professores para esta etapa da educação básica.

\section{Considerações finais}

Ao longo deste texto, procuramos mapear os saberes curriculares que são colocados em ação nas práticas de formação de professores para o Ensino Médio, desenvolvidas em cursos de licenciatura promovidos por universidades públicas e privadas situadas no Sul do Brasil. Ao tomar como ponto de partida as teorizações sociais contemporâneas, 
especialmente os escritos recentes de Gilles Lipovetsky, conseguimos diagnosticar os modos pelos quais esses processos de formação tornam-se estruturados por determinadas lógicas de estetização pedagógica. A predominância do entretenimento generalizado, a centralidade das práticas e o esmaecimento dos saberes curriculares (e de sua função pública) foram considerados na composição de nossas incursões empíricas.

Cabe enaltecer, todavia, que nossa analítica não busca assumir um lugar de denúncia ou mesmo assumimos uma atitude melancólica que remeteria a tempos passados de uma formação mais sólida. Nosso interesse esteve em criar um campo de ambivalências para pensar essa questão justamente por meio de seus excessos. Os tempos hipermodernos delineiam-se pela centralidade do indivíduo, do mercado e da tecnociência; porém, destacamos que a leveza enquanto imperativo existencial, derivada desse cenário, é temerária para pensarmos um novo horizonte para a formação de professores para o século XXI. Junto ao próprio Lipovetsky, podemos considerar que "erigida como princípio ou como ideal de vida, a leveza é tão inaceitável quanto irresponsável” (LIPOVETSKY, 2016, p. 31).

Reconhecemos a importância da formação de professores para o Ensino Médio estar ancorada em práticas profissionais e ser conduzida de forma lúdica, interativa e criativa. Entretanto, mais uma vez recorrendo ao pensador francês, encerramos este artigo com esta importante ressalva: "quando ultrapassa um determinado limite, a leveza frivola torna-se entediante e repetitiva: leveza em excesso mata a leveza” (LIPOVETSKY, 2016, p. 31).

\section{Referências}

BIESTA, Gert. Há a necessidade de (re)descobrir o ensino? In: FABRIS, Elí; DALLIGNA, Maria; SILVA, Roberto Rafael Dias da (org.). Modos de ser docente no Brasil Contemporâneo: articulações entre pesquisa e formação. São Leopoldo: Oykos, 2018. p. 21-28.

CARVALHO, Marta Maria Chagas. Modernidade Pedagógica e modelos de formação docente. São Paulo em Perspectiva, São Paulo, v. 14, n. 1, p. 111-120, 2000.

DANTAS, Jeferson Silveira. Os cadernos formativos do PNEM e suas implicações na configuração curricular do ensino médio para a juventude brasileira. Revista Brasileira de Estudos Pedagógicos, Brasília, DF, v. 98, n. 249, p. 293-310, 2017.

DUARTE, Newton. Pela superação do esfacelamento do currículo realizado pelas pedagogias relativistas. In: TORRIGLIA, Patrícia et al. (org.). Currículo: teorias e métodos. Florianópolis: UFSC, 2011. p. 245-256

GATTI, Bernadete. Formação de professores no Brasil: características e problemas. Educação \& Sociedade, Campinas, v. 31, n. 113, p. 1355-1379, 2010.

GOMES, Claudia; SOUZA, Vera. 0 PIBID e a mediação na configuração de sentidos sobre a docência. Psicologia Escolar e Educacional, São Paulo, v. 20, n. 1, p. 147-156, 2016.

HAN, Byung-Chul. Psicopolítica: neoliberalismo y nuevas técnicas de poder. Barcelona: Herder, 2014. 
Roberto Rafael Dias da SILVA

LAZZARATO, Maurizio. II governo dell'uomo indebitado: saggio sulla condizione neoliberalista. Roma: DeriveApprodi, 2013.

LIPOVETSKY, Gilles. A sociedade da decepção. São Paulo: Manole, 2007.

LIPOVETSKY, Gilles. Da leveza: rumo a uma civilização sem peso. Barueri: Manole, 2016.

LIPOVETSKY, Gilles; SERROY, Jean. A estetização do mundo: viver na era do capitalismo artista. São Paulo: Companhia das Letras, 2015.

MIALARET, Gaston. A formação dos professores. Coimbra: Almedina, 1991.

NÓVOA, Antonio. Professores: imagens do futuro presente. Lisboa: Educa, 2009.

PACHECO, José Augusto. Educação, formação e conhecimento. Porto: Porto Editora, 2014.

PETERS, Michael. Economias biopolíticas da dívida. Cadernos IHU Ideias, São Leopoldo, v. 14, n. 236, p. 1-16, 2016.

POPKEWITZ, Thomas. La práctica como teoría del cambio: investigación sobre profesores y su formación. Profesorado - Revista de Currículum y Formación del Profesorado, Granada, v. 19, n. 3, p. 429-453, 2015.

SAVIANI, Dermeval. Formação de professores: aspectos históricos e teóricos do problema no contexto brasileiro. Revista Brasileira de Educação, Rio de Janeiro, v. 14, n. 40, p. 143-155, 2009.

SILVA, Roberto Rafael Dias da. Estetização pedagógica, aprendizagens ativas e práticas curriculares no Brasil. Educação e Realidade, Porto Alegre, v. 43, p. 551-568, 2018.

SILVA, Roberto Rafael Dias da. Emocionalização, algoritmização e personalização dos itinerários formativos: como operam os dispositivos de customização curricular? Currículo Sem Fronteiras, Braga, v. 17, p. 699717, 2017.

TARDIF, Maurice; MOSCOSO, Javier Nunez. A noção de "profissional reflexivo" na educação: atualidade, usos e limites. Cadernos de Pesquisa, São Paulo, v. 48, n. 168, p. 388-411, 2018.

VICENTINI, Paula; LUGLI, Rosário. História da profissão docente no Brasil: representações em disputa. São Paulo: Cortez, 2009.

VIDAL, Diana. 0 exercício disciplinado do olhar: livros, leituras e práticas de formação docente no Instituto de Educação do Distrito Federal (1932-1937). Bragança Paulista: Edusf, 2001.

ZEICHNER, Kenneth M. Política de formação de professores nos Estados Unidos: como e por que elas afetam vários países do mundo. Belo Horizonte: Autêntica, 2013. 
Recebido em: 31.10.2018

Revisado em: 26.06.2019 Aprovado em: 14.08.2019

Roberto Rafael Dias da Silva é doutor em Educação, professor do Programa de PósGraduação em Educação da Universidade do Vale do Rio dos Sinos. 